\title{
Strategic Demand-Side Response to Wind Power Integration
}

\section{Daraeepour, Ali ; Kazempour, Seyyedjalal; Patiño-Echeverri, Dalia ; Conejo, Antonio J.}

\section{Published in:}

IEEE Transactions on Power Systems

Link to article, DOI:

10.1109/tpwrs.2015.2493984

Publication date:

2016

Document Version

Peer reviewed version

Link back to DTU Orbit

\section{Citation (APA):}

Daraeepour, A., Kazempour, S., Patiño-Echeverri, D., \& Conejo, A. J. (2016). Strategic Demand-Side Response to Wind Power Integration. IEEE Transactions on Power Systems, 31(5), 3495-3505. https://doi.org/10.1109/tpwrs.2015.2493984

\section{General rights}

Copyright and moral rights for the publications made accessible in the public portal are retained by the authors and/or other copyright owners and it is a condition of accessing publications that users recognise and abide by the legal requirements associated with these rights.

- Users may download and print one copy of any publication from the public portal for the purpose of private study or research.

- You may not further distribute the material or use it for any profit-making activity or commercial gain

- You may freely distribute the URL identifying the publication in the public portal 


\title{
Strategic Demand-Side Response to Wind Power Integration
}

\author{
Ali Daraeepour, Student Member, IEEE, S. Jalal Kazempour, Member, IEEE, Dalia Patiño-Echeverri, and \\ Antonio J. Conejo, Fellow, IEEE
}

\begin{abstract}
This paper explores the effects of allowing large, price-responsive consumers to provide reserves in a power system with significant penetration of wind energy. A bilevel optimization model represents the utility maximization problem of a large consumer, subject to a stochastic day-ahead co-optimization of energy and reserves that a system operator would solve to clear the market while considering wind power uncertainty. An examination of the market outcomes from both an illustrative and a large-scale study using this model allows analysis of a) the effects of the type of behavior of the large consumer (i.e., strategic vs competitive), b) limits on the amount of reserves it is allowed to provide, and c) variability and accuracy of characterization of wind power uncertainty.
\end{abstract}

Index Terms-Mathematical program with equilibrium constraints (MPEC), strategic consumer, wind production uncertainty, wind-integrated electricity market.

\section{INTRODUCTION}

\section{A. Background and Motivation}

I NCREASED elasticity of electricity demand is deemed to have multiple system's benefits including facilitation of integration of renewables. Similarly, it is generally accepted that allowing price responsive consumers to provide ancillary services may further improve market outcomes. However, it is possible that any positive effects may be counteracted by the strategic behavior of large consumers able to manipulate the market, particularly when they have the flexibility to provide balancing services (up and down reserves) to the grid. This impact can be even more significant under high penetration of wind energy resources which increases the need for real-time balancing services.

\section{B. Aim and Approach}

The aim of this paper is to investigate the extent to which an elastic large consumer, denoted "strategic consumer", can

Manuscript received January 13, 2015; revised June 11, 2015 and August 24, 2015; accepted October 19,2015. The work of A. Daraeepour was supported by the Duke Environmental Economics Doctoral Scholars (DEEDS) program. The work of S. J. Kazempour was supported by the US National Science Foundation under grant ECCS 1230788. Paper no. TPWRS-00059-2015.

A. Daraeepour and D. Patiño-Echeverri are with Duke University, Durham, NC 27708 USA (e-mail: a.daraeepour@duke.edu; dalia.patino@duke.edu).

S. J. Kazempour is with the Technical University of Denmark, Kgs. Lyngby, Denmark (e-mail: seykaz@elektro.dtu.dk).

A. J. Conejo is with the Integrated System Engineering and Electrical and Computer Engineering Departments, The Ohio State University, Columbus, $\mathrm{OH}$ 43210 USA (e-mail: conejonavarro.1@osu.edu).

Color versions of one or more of the figures in this paper are available online at http://ieeexplore.ieee.org.

Digital Object Identifier 10.1109/TPWRS.2015.2493984 exercise its market power in an energy-only, wind-integrated electricity market. We define a strategic consumer as an entity that either owns large loads in different locations of the electricity grid or a non-profit aggregator that submits purchase bids on behalf of its loads. These entities, by definition, are obliged to serve their loads while having control over their consumption through diverse instruments. Examples of such an entity are large corporations with industrial plants like aluminum, steel, and ferro alloys production plants; liquefied air companies; motor vehicle manufacturing companies; pulp, paper, and paperboard mills; etc.

We develop a stochastic complementarity model (based on a bilevel optimization problem) representing the optimal bidding strategy of the strategic consumer, considering wind power production uncertainty and endogenous formation of clearing prices of electricity. The proposed bilevel programming approach includes an upper-level (UL) problem, representing expected utility maximization of the strategic consumer (as the only player behaving strategically), constrained to a lower-level (LL) problem, representing actual day-ahead market (DAM) clearing and balancing operation of the grid. The UL problem depends on clearing prices coming from the LL problem, and the LL problem is influenced by day-ahead bidding curves determined in the UL problem. The strategic consumer owns large number of loads that do not need to be fully supplied.

The considered pool in this paper is cleared one day prior to power delivery on an hourly basis. The pool clearing algorithm is a single-period network-constrained auction, which is recast as a two-stage stochastic programming problem to incorporate the integration of wind power producers and the uncertainty of their production. The first stage of this model represents the actual DAM clearing and the second stage models the balancing operation of the system for different realizations of wind power production. Indeed, DAM decisions are made accounting for expected balancing cost of the system due to uncertain wind fluctuations. Depending on the real-time realization of wind power production, up or down reserves are deployed to balance generation and demand during the real-time operation of the system. Reserve deployment refers to changes in energy generation/consumption levels of units/loads between the first (day-ahead) and second (balancing) stages. Units/loads reserve a part of their generation/consumption capacity, called reserve capacity, in the day-ahead stage to be converted to energy in the balancing stage, offsetting wind power variations. The rationale of the stochastic market clearing model is investigated using a generic mathematical framework in [1]. The stochastic market clearing model has generally two main differences with respect to the existing deterministic models traditionally used in the electricity markets: 1) estimation of the reserve requirements 
and 2) dispatch of energy and deployment of reserves. In deterministic market clearing models, reserve requirements are input parameters reflecting a target that system's operators pre-specify based on reliability criteria and without any consideration of the current costs of such services and/or updated information on the uncertainty and variability of intermittent energy resources. In contrast, in a stochastic market clearing model reserve requirements are endogenously determined through simulating the balancing operation of the system under different scenarios. The second difference between the stochastic and deterministic modeling stems from the dispatch of energy and reserves. The stochastic model provides an optimal pre-positioning of generating units and loads to manage the uncertain events in the balancing stage of the system. Consequently, and different from the deterministic modeling, stochastic models would not necessarily schedule all the day-ahead forecasted wind power production in the DAM, and instead, would schedule a level of wind power production determined after considering its variability and uncertainty, and the costs and availability that required reserves for managing it [1]-[6]. The pricing scheme of the stochastic model is proved to ensure generation cost recovery and revenue adequacy in expectation. A lossless dc representation of the network is embodied in both stages of the pool clearing algorithm so both day-ahead and balancing prices are locational marginal prices (LMPs).

\section{Literature Review and Contributions}

One thread of research related to this work is concerned with demand-side bidding strategy in electricity markets. Most literature in this domain regards electricity purchasers as price takers. For instance, references [7], [8], and [9] optimize the bidding strategy of a price-responsive retailer, with different responsiveness levels to electricity prices.

Similarly, [10] and [11] optimize the contracting policies for energy purchase of an energy buyer participating in forward and day-ahead markets using stochastic programming models. In addition, [12] designs the robust electricity procurement strategy of a large consumer in a DAM and a subsequent adjustment market using information gap decision theory. However, very little attention has been paid to the strategic demand-side bidding with endogenous formation of electricity prices. [13] proposes a non-linear programming approach (where optimality of its solution is not guaranteed) for the optimal bidding strategy of a retailer procuring electricity in the DAM and several subsequent intra-day markets. The retailer's impact on the clearing prices is represented through its residual offer curves in each market. [14] proposes a complementarity bilevel model for deriving strategic bidding curves of a large consumer, supplying its demand in a day-ahead pool, under the uncertainty of supply offer curves of producers.

Complementarity modeling, or specifically bilevel optimization has been applied before to different electricity market problems. This technique has been used to study the offering strategy of a producer [15], the offering strategy of investor-owned storage units [16], the bidding strategy of a large consumer participating in day-ahead markets [14], strategic generation investment [17], [18], transmission expansion planning [19], [20], vulnerability assessment [21], yearly generation maintenance scheduling [22], and yearly transmission maintenance scheduling [23]. Among these papers, [14] is the only one investigating the strategic behavior of a large price-responsive consumer through complementarity modeling. However, [14] determines the strategic day-ahead bidding curves without considering the benefits the strategic consumer can obtain from provisioning balancing services. Moreover, [14] also leaves out of the analysis the uncertainty of wind power production and its impacts on provision of balancing services and other market outcomes determining the benefits of the strategic consumer. To fill these gaps, this paper extends the model presented in [14] in three ways: a) it allows demand-side resources to provide reserves, b) it accounts for the benefits of this provision in the determination of the bid of the strategic consumer, and c) it accounts for the uncertainty on wind power generation and its impacts on the strategic consumer's ability to manipulate the market to its benefit. To the best of our knowledge, our approach of using a two-stage stochastic market clearing model in the lower-level program of a complementarity model to determine the day-ahead dispatch of energy and reserves under wind power uncertainty is the first of its kind. None of the previous works have addressed the impacts of the participation of the strategic consumer on the reserve provision and the impacts of wind power production uncertainty on the design of this consumer's day-ahead bidding strategy. Accordingly, the contributions of this paper are threefold:

1) A two-stage stochastic complementarity model that derives an optimal bidding strategy for a large strategic consumer in an electricity market (including day-ahead trading stage and real-time operation) under wind power production uncertainty, and demand-side reserve provision.

2) A transformation of the proposed stochastic complementarity model into an equivalent mixed-integer linear programming (MILP) problem.

3) Use of the proposed model to explore the effects of allowing large consumers to participate in the reserve's market under uncertainty on wind-power production.

\section{Paper Organization}

The remainder of the paper is organized as follows. Section II presents features and assumptions of the proposed strategic bidding model. Mathematical formulation of the model, including the bilevel model, its corresponding Mathematical Program with Equilibrium Constraints (MPEC) and its equivalent MILP are described in Section III. Section IV provides and discusses the results from case studies. Section V concludes the paper.

\section{Model FeAtures AND ASSUMPtions}

The main modeling features and assumptions of this paper are as follows:

1) The strategic consumer bids strategically the demand of load $q$ in the DAM at a price $B_{q}^{\mathrm{S}}$, while offers competitively its reserve deployment at $U_{q}^{S}$ which is identical to its marginal utility.

2) Each load and each generating unit offers both up and down reserves at an identical price. This assumption is made due to lack of data on offer prices, nevertheless if it was revised to consider asymmetrical offer prices for the up and down reserves it is unlikely the conclusions of this paper would change. 
3) All loads/generating units submit their energy bids/offers to the DAM, while only flexible loads/generating units offer reserve deployment in the balancing stage.

4) Among all potential uncertainties, only wind power production uncertainty is taken into account and characterized through a finite set of plausible scenarios.

5) Scheduled wind production in the DAM for each wind farm is limited to the expected wind power production of that wind farm.

6) Since the clearing algorithm of the pool is a single-hour auction, the inter-temporal constraints of generating units and loads are not considered.

7) Only one single bidding/offering block is considered for each load/generating unit.

8) Only competitive loads are considered for involuntarily load curtailment in the balancing stage so that they are paid for their curtailed load at their value of lost load (VOLL).

9) The supply side is assumed to be perfectly competitive so all generating units submit their marginal costs and their respective offers.

\section{MODEL FORMULATION}

This section presents the notation, the formulation of the bilevel model, and the corresponding MPEC in nonlinear and linear forms.

\section{NOTATION}

\section{A. Indices}

$q$

$l$

from 1 to $N_{l}$

$g \quad$ Index for generating units running from 1 to $N_{g}$.

$k \quad$ Index for wind farms running from 1 to $N_{k}$.

$n, m \quad$ Indices for buses running from 1 to $N$, and from 1 to $M$, respectively.

$\omega \quad$ Index for wind power scenarios running from 1 to $N_{\omega}$.

\section{B. Sets}

$\mathcal{D}^{\mathrm{S}} \quad$ Set of loads of the strategic consumer.

$\mathcal{D}^{\mathrm{C}} \quad$ Set of loads of competitive consumers.

$\mathcal{G} \quad$ Set of generating units.

$\mathcal{K} \quad$ Set of wind farms.

$\Psi_{n} \quad$ Set of system buses adjacent to bus $n$.

Sets $\mathcal{D}^{\mathrm{S}}, \mathcal{D}^{\mathrm{C}}, \mathcal{G}$ and $\mathcal{K}$ include subscript $n$ if referring to the set of loads/units/farms located at bus $n$.

\section{Constants}

$\phi_{\omega} \quad$ Probability of scenario $\omega$.

$O_{g} \quad$ Price offer by generating unit $g \in \mathcal{G}[\$ / \mathrm{MWh}$, equal to its marginal cost.

$U_{l}^{\mathrm{C}} \quad$ Price bid by competitive load $l \in \mathcal{D}^{\mathrm{C}}[\$ / \mathrm{MWh}]$, equal to its marginal utility.

$U_{q}^{\mathrm{S}} \quad$ Marginal utility of load $q \in \mathcal{D}^{\mathrm{S}}$ of the strategic consumer [\$/MWh].

$B^{\text {Cap }} \quad$ Price cap for bids of the strategic consumer [\$/MWh].

$\bar{P}_{g}^{\mathrm{G}} \quad$ Capacity of generating unit $g \in \mathcal{G}[\mathrm{MW}]$.

$\bar{P}_{q}^{\mathrm{S}}$

$\bar{P}_{l}^{\mathrm{C}}$

$\bar{R}_{g}^{\mathrm{G}}$

$\bar{R}_{g}^{\mathrm{G}}$

$\bar{R}_{q}^{\mathrm{S}}$

$\bar{R}_{q}^{\mathrm{S}}$

$\bar{R}_{l}^{\mathrm{C}^{\mathrm{U}}}$

$\bar{R}_{l}^{\mathrm{C}^{\mathrm{D}}}$

$V_{l}$

$W_{k \omega}^{\mathrm{act}}$

Maximum demand of load $q \in \mathcal{D}^{\mathrm{S}}$ of the strategic consumer [MW].

Maximum demand of competitive load $l$ $\in \mathcal{D}^{\mathrm{C}}[\mathrm{MW}]$.

Maximum up reserve to be provided by generating unit $g \in \mathcal{G}[\mathrm{MW}]$.

Maximum down reserve to be provided by generating unit $g \in \mathcal{G}[\mathrm{MW}]$.

Maximum up reserve to be provided by load $q \in \mathcal{D}^{\mathrm{S}}$ of the strategic consumer [MW].

Maximum down reserve to be provided by load $q$ $\in \mathcal{D}^{\mathrm{S}}$ of the strategic consumer [MW].

Maximum up reserve to be provided by competitive load $l \in \mathcal{D}^{\mathrm{C}}[\mathrm{MW}]$.

Maximum down reserve to be provided by competitive load $l \in \mathcal{D}^{\mathrm{C}}[\mathrm{MW}]$.

Value of lost load for competitive load $l$

$\in \mathcal{D}^{\mathrm{C}}[\$ / \mathrm{MWh}]$.

$\bar{W}_{k} \quad$ Maximum power production of wind farm $k \in \mathcal{K}$ to be scheduled in the DAM [MW].

$S_{n m} \quad$ Susceptance of transmission line $(n, m)[\mathrm{S}]$.

$F_{n m} \quad$ Capacity of transmission line $(n, m)[\mathrm{MW}]$.

\section{Variables}

$P_{g}^{\mathrm{G}}$

$P_{q}^{\mathrm{S}}$

$P_{l}^{\mathrm{C}}$

$W_{k}$

$r_{g \omega}^{\mathrm{G}}$

$r_{q \omega}^{\mathrm{S}}$

$r_{l \omega}^{\mathrm{C}}$

$p_{l \omega}^{\text {Shed }}$

$w_{k \omega}^{\text {Spill }}$

$B_{q}^{\mathrm{S}}$

$\theta_{n}^{\mathrm{DA}}$

$\theta_{n \omega}^{\mathrm{B}}$

$\alpha_{n}^{\mathrm{DA}}$

$\alpha_{n \omega}^{\mathrm{B}}$
Scheduled production of generating unit $g \in \mathcal{G}$ in the DAM [MW].

Cleared power to be consumed by load $q \in \mathcal{D}^{\mathrm{S}}$ of the strategic consumer in the DAM [MW].

Cleared power to be consumed by competitive load $l \in \mathcal{D}^{\mathrm{C}}$ in the DAM [MW].

Scheduled wind production of farm $k \in \mathcal{K}$ in the DAM [MW].

Deployed reserve by generating unit $g \in \mathcal{G}$ in the balancing stage under scenario $\omega[\mathrm{MW}]$.

Deployed reserve by load $q \in \mathcal{D}^{\mathrm{S}}$ of the strategic consumer in the balancing stage under scenario $\omega[\mathrm{MW}]$.

Deployed reserve by competitive load $l \in \mathcal{D}^{\mathrm{C}}$ in the balancing stage under scenario $\omega[\mathrm{MW}]$.

Involuntarily load shed of competitive load $l \in \mathcal{D}^{\mathrm{C}}$ in the balancing stage under scenario $\omega[\mathrm{MW}]$. Wind power production spillage of farm $k \in \mathcal{K}$ in the balancing stage under scenario $\omega[\mathrm{MW}]$.

Price bid by load $q \in \mathcal{D}^{\mathrm{S}}$ of the strategic consumer [\$/MWh].

Voltage angle of bus $n$ in the DAM [rad].

Voltage angle of bus $n$ in the balancing stage under scenario $\omega[\mathrm{rad}]$.

Day-ahead locational marginal price at bus $n$ [\$/MWh].

Probability-weighted balancing locational marginal price at bus $n$ under scenario $\omega[\$ / \mathrm{MWh}]$. 


\section{E. Bilevel Model}

The optimal bidding strategy of a strategic consumer is designed using the following bilevel optimization model formulated in (1)-(2). Equations (1) and (2) represent the UL and LL problems, respectively. $\Xi_{\text {Primal }}^{\mathrm{LL}}=$ $\left\{P_{g}^{\mathrm{G}}, P_{q}^{\mathrm{S}}, P_{l}^{\mathrm{C}}, W_{k}, r_{g \omega}^{\mathrm{G}}, r_{q \omega}^{\mathrm{S}}, r_{l \omega}^{\mathrm{C}}, p_{l \omega}^{\mathrm{Shed}}, w_{k \omega}^{\mathrm{Spill}}, \theta_{n}^{\mathrm{DA}}, \theta_{n \omega}^{\mathrm{B}}\right\}$ represents the primal set of variables of the LL problem, and $\Xi_{\text {Dual }}^{\mathrm{LL}}$ indicates the LL problem's set of dual variables. The corresponding dual variable of each constraint is after the constraint following a colon. Also, $\Xi^{\mathrm{UL}}=\left\{\Xi_{\text {Primal }}^{\mathrm{LL}}, \Xi_{\text {Dual }}^{\mathrm{LL}}, B_{q}^{\mathrm{S}}\right\}$ represents the primal set of the UL problem's variables. Note that $B_{q}^{\mathrm{S}}$ (bid price of the strategic consumer) is a decision variable within the UL problem and a parameter in the LL problem so that they are fixed bidding decisions in the LL problem. Therefore, the LL problem is linear and thus convex.

$$
\begin{aligned}
\underset{\Xi^{\mathrm{UL}}}{\operatorname{Maximize}} \sum_{q \in \mathcal{D}^{\mathrm{S}}}\left\{P_{q}^{\mathrm{S}}\left(U_{q}^{\mathrm{S}}-\alpha_{n: q \in \mathcal{D}_{n}^{\mathrm{S}}}^{\mathrm{DA}}\right)\right. \\
\quad+\sum_{\omega} \phi_{\omega} r_{q \omega}^{\mathrm{S}}\left(\frac{\left.\alpha_{\left(n: q \in \mathcal{D}_{n}^{\mathrm{S}}\right) \omega}^{\mathrm{B}}-U_{q}^{\mathrm{S}}\right)}{\phi_{\omega}}\right\}
\end{aligned}
$$

subject to:

$$
\begin{gathered}
0 \leq B_{q}^{\mathrm{S}} \leq B^{\text {cap }} \quad \forall q \in \mathcal{D}^{\mathrm{S}} \\
\alpha_{n}^{\mathrm{DA}}, \alpha_{n \omega}^{\mathrm{B}}, P_{q}^{\mathrm{S}}, r_{q \omega}^{\mathrm{S}} \in \arg \underset{\Xi_{\mathrm{Primal}}^{\mathrm{LL}}}{\operatorname{minimize}}\{ \\
\sum_{\omega} \phi_{\omega}\left\{\sum_{g \in \mathcal{G}}\left[O_{g}\left(P_{g}^{\mathrm{G}}+r_{g \omega}^{\mathrm{G}}\right)\right]-\sum_{q \in \mathcal{D}^{\mathrm{S}}}\left[B_{q}^{\mathrm{S}} P_{q}^{\mathrm{S}}-U_{q}^{\mathrm{S}} r_{q \omega}^{\mathrm{S}}\right]\right. \\
\left.-\sum_{l \in \mathcal{D}^{\mathrm{C}}}\left[U_{l}^{\mathrm{C}}\left(P_{l}^{\mathrm{C}}-r_{l \omega}^{\mathrm{C}}\right)-V_{l} p_{l \omega}^{\mathrm{Shed}}\right]\right\}
\end{gathered}
$$

subject to:

$$
\begin{aligned}
& \sum_{q \in \mathcal{D}_{n}^{\mathrm{S}}} P_{q}^{\mathrm{S}}+\sum_{l \in \mathcal{D}_{n}^{\mathrm{C}}} P_{l}^{\mathrm{C}}+\sum_{m \in \Psi_{n}} S_{n m}\left(\theta_{n}^{\mathrm{DA}}-\theta_{m}^{\mathrm{DA}}\right) \\
& -\sum_{g \in \mathcal{G}_{n}} P_{g}^{\mathrm{G}}-\sum_{k \in \mathcal{K}_{n}} W_{k}=0 \quad: \alpha_{n}^{\mathrm{DA}} \forall n \\
& \sum_{m \in \Psi_{n}} S_{n m}\left(\theta_{n \omega}^{\mathrm{B}}-\theta_{m \omega}^{\mathrm{B}}-\theta_{n}^{\mathrm{DA}}+\theta_{m}^{\mathrm{DA}}\right) \\
& -\sum_{g \in \mathcal{G}_{n}} r_{g \omega}^{\mathrm{G}}-\sum_{q \in \mathcal{D}_{n}^{\mathrm{S}}} r_{q \omega}^{\mathrm{S}}-\sum_{l \in \mathcal{D}_{n}^{\mathrm{C}}}\left(r_{l \omega}^{\mathrm{C}}+p_{l \omega}^{\mathrm{Shed}}\right) \\
& -\sum_{k \in \mathcal{K}_{n}}\left(W_{k \omega}^{\mathrm{act}}-W_{k}-w_{k \omega}^{\mathrm{Spill}}\right)=0 \quad: \alpha_{n \omega}^{\mathrm{B}} \quad \forall n, \forall \omega \\
& 0 \leq P_{g}^{\mathrm{G}} \leq \bar{P}_{g}^{\mathrm{G}} \quad: \underline{\mu}_{g}^{\mathrm{G}}, \bar{\mu}_{g}^{\mathrm{G}} \quad \forall g \in \mathcal{G} \\
& 0 \leq W_{k} \leq \bar{W}_{k} \quad: \underline{\mu}_{k}^{\mathrm{W}}, \bar{\mu}_{k}^{\mathrm{W}} \quad \forall k \in \mathcal{K} \\
& 0 \leq P_{q}^{\mathrm{S}} \leq \bar{P}_{q}^{\mathrm{S}} \quad: \underline{\mu}_{q}^{\mathrm{S}}, \bar{\mu}_{q}^{\mathrm{S}} \quad \forall q \in \mathcal{D}^{\mathrm{S}} \\
& 0 \leq P_{l}^{\mathrm{C}} \leq \bar{P}_{l}^{\mathrm{C}} \quad: \underline{\mu}_{l}^{\mathrm{C}}, \bar{\mu}_{l}^{\mathrm{C}} \quad \forall l \in \mathcal{D}^{\mathrm{C}} \\
& S_{n m}\left(\theta_{n}^{\mathrm{DA}}-\theta_{m}^{\mathrm{DA}}\right) \leq F_{n m} \quad: \zeta_{n m}^{\mathrm{DA}} \quad \forall n, \forall m \in \Psi_{n} \\
& -\pi \leq \theta_{n}^{\mathrm{DA}} \leq \pi \quad: \underline{\delta}_{n}^{\mathrm{DA}}, \bar{\delta}_{n}^{\mathrm{DA}} \quad \forall n \\
& \theta_{n=1}^{\mathrm{DA}}=0 \quad: \delta^{\mathrm{DA}(\mathrm{n}=1)} \\
& -P_{g}^{\mathrm{G}} \leq r_{g \omega}^{\mathrm{G}} \leq\left(\bar{P}_{g}^{\mathrm{G}}-P_{g}^{\mathrm{G}}\right): \underline{v}_{g \omega}^{\mathrm{G}}, \bar{v}_{g \omega}^{\mathrm{G}} \quad \forall g \in \mathcal{G}, \forall \omega \\
& -\bar{R}_{g}^{\mathrm{G}^{\mathrm{D}}} \leq r_{g \omega}^{\mathrm{G}} \leq \bar{R}_{g}^{\mathrm{G}^{\mathrm{U}}} \quad: \underline{\eta}_{g \omega}^{\mathrm{G}}, \bar{\eta}_{g \omega}^{\mathrm{G}} \quad \forall g \in \mathcal{G}, \forall \omega
\end{aligned}
$$

$$
\begin{aligned}
& \left(P_{q}^{\mathrm{S}}-\bar{P}_{q}^{\mathrm{S}}\right) \leq r_{q \omega}^{\mathrm{S}} \leq P_{q}^{\mathrm{S}}: \underline{v}_{q \omega}^{\mathrm{S}}, \bar{v}_{q \omega}^{\mathrm{S}} \quad \forall q \in \mathcal{D}^{\mathrm{S}}, \forall \omega \\
& -\bar{R}_{q}^{\mathrm{S}^{\mathrm{D}}} \leq r_{q \omega}^{\mathrm{S}} \leq \bar{R}_{q}^{\mathrm{S}^{\mathrm{U}}} \quad: \underline{\eta}_{q \omega}^{\mathrm{S}}, \bar{\eta}_{q \omega}^{\mathrm{S}} \quad \forall q \in \mathcal{D}^{\mathrm{S}}, \forall \omega \\
& \left(P_{l}^{\mathrm{C}}-\bar{P}_{l}^{\mathrm{C}}\right) \leq r_{l \omega}^{\mathrm{C}} \leq P_{l}^{\mathrm{C}} \quad: \underline{v}_{l \omega}^{\mathrm{C}}, \bar{v}_{l \omega}^{\mathrm{C}} \quad \forall l \in \mathcal{D}^{\mathrm{C}}, \forall \omega \\
& -\bar{R}_{l}^{\mathrm{C}^{\mathrm{D}}} \leq r_{l \omega}^{\mathrm{C}} \leq \bar{R}_{l}^{\mathrm{C}^{\mathrm{U}}} \quad: \underline{\eta}_{l \omega}^{\mathrm{C}}, \bar{\eta}_{l \omega}^{\mathrm{C}} \quad \forall l \in \mathcal{D}^{\mathrm{C}}, \forall \omega \\
& 0 \leq p_{l \omega}^{\mathrm{Shed}} \leq\left(P_{l}^{\mathrm{C}}-r_{l \omega}^{\mathrm{C}}\right) \quad: \underline{\eta}_{l \omega}^{\mathrm{Shed}}, \bar{\eta}_{l \omega}^{\mathrm{Shed}} \forall l \in \mathcal{D}^{\mathrm{C}}, \forall \omega(2 \mathrm{q}) \\
& 0 \leq w_{k \omega}^{\mathrm{Spill}} \leq W_{k \omega}^{\mathrm{act}} \quad: \underline{\eta}_{k \omega}^{\mathrm{W}}, \bar{\eta}_{k \omega}^{\mathrm{W}} \quad \forall k \in \mathcal{K}, \forall \omega \\
& S_{n m}\left(\theta_{n \omega}^{\mathrm{B}}-\theta_{m \omega}^{\mathrm{B}}\right) \leq F_{n m}: \zeta_{n m \omega}^{\mathrm{B}} \quad \forall n, \forall m \in \Omega_{n}, \forall \omega \\
& -\pi \leq \theta_{n \omega}^{\mathrm{B}} \leq \pi \quad: \underline{\delta}_{n \omega}^{\mathrm{B}}, \bar{\delta}_{n \omega}^{\mathrm{B}} \quad \forall n, \forall \omega \\
& \left.\theta_{(n=1) \omega}^{\mathrm{B}}=0 \quad: \delta_{\omega}^{\mathrm{B}(\mathrm{n}=1)} \quad\right\} \text {. }
\end{aligned}
$$

In the UL problem, objective function (1a) represents the total expected utility of the strategic consumer for a single time period that consists of two terms: the first term corresponds to the strategic consumer's utility in the DAM and the second term models the strategic consumer's expected utility in the balancing stage over the set of scenarios. The consumer's utility in the DAM is calculated by multiplying the consumption quantities scheduled in the DAM for the consumer $\left(P_{q}^{\mathrm{S}}\right)$ by the difference between the consumer's bid ( $U_{q}^{\mathrm{S}}$, the price it is willing to pay), and the day-ahead LMPs $\left(\alpha_{n}^{\mathrm{DA}}\right)$. Likewise, the balancing LMPs $\left(\alpha_{n \omega}^{\mathrm{B}} / \phi_{\omega}\right)$ and deployed reserves $\left(r_{q \omega}^{\mathrm{S}}\right)$ are used to determine the strategic consumer's utility under each scenario, and the expected utility over the set of scenarios. Note that $\alpha_{n \omega}^{\mathrm{B}} / \phi_{\omega}$ is the probability-removed balancing LMP at bus $n$ for scenario $\omega$ where $\phi_{\omega}$ is the probability of that scenario. Constraint (1b) ensures non-negativity of the strategic consumer's bid price and enforces that to be less than the price cap of the pool. The LL problem, which models the clearing of the pool, is presented in $(2 \mathrm{a})-(2 \mathrm{u})$. Equation $(2 \mathrm{a})$ represents the objective function, which minimizes the minus of declared expected social welfare. Constraints $(2 \mathrm{~b})$ to $(2 \mathrm{u})$ represent the constraints of the pool clearing model. Note that scenario-independent constraints (2b) and $(2 \mathrm{~d})-(2 \mathrm{j})$ correspond to the first stage (i.e., DAM clearing), while scenario-dependent constraints $(2 \mathrm{c})$ and $(2 \mathrm{k})-(2 \mathrm{u})$ pertain to the balancing stage. Constraints $(2 b)$ and $(2 c)$ represent the balance constraints in the DAM and balancing stage for every bus $n$, respectively. Dual variables of these constraints for the specific bus $n$, i.e., $\alpha_{n}^{\mathrm{DA}}$ and $\alpha_{n \omega}^{\mathrm{B}}$, are the day-ahead and balancing LMPs of bus $n$, respectively. Constraints (2d) and (2e) bound the scheduled production for conventional and wind power generating units in the DAM to their minimum and maximum limits. The maximum production that can be scheduled in the DAM for a conventional unit is limited to its installed capacity, though the maximum production that is scheduled for a wind farm is limited to its expected production. Constraints (2f) and $(2 \mathrm{~g})$ bound the minimum and maximum scheduled consumption in the DAM, respectively, for strategic and competitive loads. Constraint ( $2 \mathrm{~h}$ ) enforces transmission constraints in the DAM. Constraint (2i) enforces the upper and lower bounds of the voltage angles in the DAM. Constraint $(2 \mathrm{j})$ identifies bus $n=1$ as the voltage angle's reference in the DAM.

Constraints $(2 \mathrm{k})-(2 \mathrm{u})$ are all scenario-dependent representing the balancing stage constraints under different scenarios. Constraints (2k) and (2l) bound the maximum up and down reserve that conventional generating units can deploy. Constraints 
(2m)-(2p) represent the maximum up and down reserve that strategic and competitive loads deploy, respectively. Constraints $(2 q)$ and $(2 r)$ enforce the amount of corrective actions, including involuntary load shedding and wind spillage, to be within specific limits. Load shedding from the competitive load $l$ in scenario $\omega$ must be lower than its adjusted consumption under scenario $\omega$. Constraint $(2 s)$ enforces transmission constraints in the balancing stage. Constraint $(2 \mathrm{t})$ enforces the upper and lower bounds of the voltage angles in the balancing stage. Constraint $(2 \mathrm{u})$ identifies bus $n=1$ as the voltage angle's reference in the balancing stage under scenario $\omega$.

\section{F. $M P E C$}

The linearity of the LL problem (2) allows replacing it by its Karush-Kuhn-Tucker (KKT) optimality conditions. This transformation renders an MPEC as given by (3)-(4) below:

$$
\underset{\Xi^{\mathrm{UL}}}{\operatorname{Maximize}}(1 \mathrm{a})
$$

subject to:

$$
\begin{aligned}
& (1 \mathrm{~b}),(2 \mathrm{~b}),(2 \mathrm{c}),(2 \mathrm{j}),(2 \mathrm{u}) \\
& O_{g}-\alpha_{n: g \in \mathcal{G}_{n}}^{\mathrm{DA}}-\underline{\mu}_{g}^{\mathrm{G}}+\bar{\mu}_{g}^{\mathrm{G}}-\sum_{\omega}\left(\underline{v}_{g \omega}^{\mathrm{G}}-\bar{v}_{g \omega}^{\mathrm{G}}\right)=0 \\
& \forall g \in \mathcal{G} \\
& \phi_{\omega} O_{g}-\alpha_{\left(n: g \in \mathcal{G}_{n}\right) \omega}^{\mathrm{B}}-\underline{v}_{g \omega}^{\mathrm{G}}+\bar{v}_{g \omega}^{\mathrm{G}}-\underline{\eta}_{g \omega}^{\mathrm{G}}+\bar{\eta}_{g \omega}^{\mathrm{G}}=0 \\
& \forall g \in \mathcal{G}, \forall \omega \\
& -\alpha_{n: k \in \mathcal{K}_{n}}^{\mathrm{DA}}+\sum_{\omega} \alpha_{\left(n: k \in \mathcal{K}_{n}\right) \omega}^{\mathrm{B}}-\underline{\mu}_{k}^{\mathrm{W}}+\bar{\mu}_{k}^{\mathrm{W}}=0 \\
& \forall k \in \mathcal{K} \\
& \alpha_{\left(n: k \in \mathcal{K}_{n}\right) \omega}^{\mathrm{B}}-\underline{\eta}_{k \omega}^{\mathrm{W}}+\bar{\eta}_{k \omega}^{\mathrm{W}}=0 \quad \forall k \in \mathcal{K}, \forall \omega \\
& -B_{q}^{\mathrm{S}}+\alpha_{n: q \in \mathcal{D}_{n}^{\mathrm{S}}}^{\mathrm{DA}}-\underline{\mu}_{q}^{\mathrm{S}}+\bar{\mu}_{q}^{\mathrm{S}}+\sum_{\omega}\left(\underline{v}_{q \omega}^{\mathrm{S}}-\bar{v}_{q \omega}^{\mathrm{S}}\right)=0 \\
& \forall q \in \mathcal{D}^{\mathrm{S}} \\
& \phi_{\omega} U_{q}^{\mathrm{S}}-\alpha_{\left(n: q \in \mathcal{D}_{n}^{\mathrm{S}}\right) \omega}^{B}-\underline{v}_{q \omega}^{\mathrm{S}}+\bar{v}_{q \omega}^{\mathrm{S}}-\underline{\eta}_{q \omega}^{\mathrm{S}}+\bar{\eta}_{q \omega}^{\mathrm{S}}=0 \\
& \forall q \in \mathcal{D}^{\mathrm{S}}, \forall \omega \\
& -U_{l}^{\mathrm{C}}+\alpha_{n: l \in \mathcal{D}_{n}^{\mathrm{C}}}^{\mathrm{DA}}-\underline{\mu}_{l}^{\mathrm{C}}+\bar{\mu}_{l}^{\mathrm{C}}+\sum_{\omega}\left(\underline{v}_{l \omega}^{\mathrm{C}}-\bar{v}_{l \omega}^{\mathrm{C}}\right. \\
& \left.-\bar{\eta}_{l \omega}^{\text {Shed }}\right)=0 \quad \forall l \in \mathcal{D}^{\mathrm{C}} \\
& \phi_{\omega} U_{l}^{\mathrm{C}}-\alpha_{\left(n: l \in \mathcal{D}_{n}^{\mathrm{S}}\right) \omega}^{\mathrm{B}}-\underline{v}_{l \omega}^{\mathrm{C}}+\bar{v}_{l \omega}^{\mathrm{C}}-\underline{\eta}_{l \omega}^{\mathrm{C}}+\bar{\eta}_{l \omega}^{\mathrm{C}} \\
& +\bar{\eta}_{l \omega}^{\text {Shed }}=0 \quad \forall l \in \mathcal{D}^{\mathrm{C}}, \forall \omega \\
& \phi_{\omega} V_{l}-\alpha_{\left(n: l \in \mathcal{D}_{n}^{\mathrm{C}}\right) \omega}^{\mathrm{B}}-\underline{\eta}_{l \omega}^{\mathrm{Shed}}+\bar{\eta}_{l \omega}^{\mathrm{Shed}}=0 \\
& \forall l \in \mathcal{D}^{\mathrm{C}}, \forall \omega \\
& \sum_{m \in \Psi_{n}} S_{n m}\left(\alpha_{n}^{\mathrm{DA}}-\alpha_{m}^{\mathrm{DA}}\right)-\sum_{\left(m \in \Psi_{n}\right) \omega} S_{n m}\left(\alpha_{n \omega}^{\mathrm{B}}-\alpha_{m \omega}^{\mathrm{B}}\right) \\
& +\sum_{m \in \Psi_{n}} S_{n m}\left(\zeta_{n m}^{\mathrm{DA}}-\zeta_{m n}^{\mathrm{DA}}\right) \\
& +\bar{\delta}_{n}^{\mathrm{DA}}-\underline{\delta}_{n}^{\mathrm{DA}}+\left(\delta^{\mathrm{DA}(\mathrm{n}=1)}\right)_{n=1}=0 \quad \forall n \\
& \sum_{m \in \Psi_{n}} S_{n m}\left(\alpha_{n \omega}^{\mathrm{B}}-\alpha_{m \omega}^{\mathrm{B}}\right)+\sum_{m \in \Psi_{n}} S_{n m}\left(\zeta_{n m \omega}^{\mathrm{B}}-\zeta_{m n \omega}^{\mathrm{B}}\right) \\
& +\bar{\delta}_{n \omega}^{\mathrm{B}}-\underline{\delta}_{n \omega}^{\mathrm{B}}+\left(\delta_{\omega}^{\mathrm{B}(\mathrm{n}=1)}\right)_{n=1}=0 \quad \forall n, \forall \omega \\
& 0 \leq P_{g}^{\mathrm{G}} \perp \underline{\mu}_{g}^{\mathrm{G}} \geq 0 \quad \forall g \in \mathcal{G}
\end{aligned}
$$

$$
\begin{aligned}
& 0 \leq\left(\bar{P}_{g}^{\mathrm{G}}-P_{g}^{\mathrm{G}}\right) \perp \bar{\mu}_{g}^{\mathrm{G}} \geq 0 \quad \forall g \in \mathcal{G} \\
& 0 \leq W_{k} \perp \underline{\mu}_{k}^{\mathrm{W}} \geq 0 \quad \forall k \in \mathcal{K} \\
& 0 \leq\left(\bar{W}_{k}-W_{k}\right) \perp \bar{\mu}_{k}^{\mathrm{W}} \geq 0 \quad \forall k \in \mathcal{K} \\
& 0 \leq P_{q}^{\mathrm{S}} \perp \underline{\mu}_{q}^{\mathrm{S}} \geq 0 \quad \forall q \in \mathcal{D}^{\mathrm{S}} \\
& 0 \leq\left(\bar{P}_{q}^{\mathrm{S}}-P_{q}^{\mathrm{S}}\right) \perp \bar{\mu}_{q}^{\mathrm{S}} \geq 0 \quad \forall q \in \mathcal{D}^{\mathrm{S}} \\
& 0 \leq P_{l}^{\mathrm{C}} \perp \underline{\mu}_{l}^{\mathrm{C}} \geq 0 \quad \forall l \in \mathcal{D}^{\mathrm{C}} \\
& 0 \leq\left(\bar{P}_{l}^{\mathrm{C}}-P_{l}^{\mathrm{C}}\right) \perp \bar{\mu}_{l}^{\mathrm{C}} \geq 0 \quad \forall l \in \mathcal{D}^{\mathrm{C}} \\
& 0 \leq\left[F_{n m}-S_{n m}\left(\theta_{n}^{\mathrm{DA}}-\theta_{m}^{\mathrm{DA}}\right)\right] \perp \zeta_{n m}^{\mathrm{DA}} \geq 0 \\
& \forall n, \forall m \in \Psi_{n} \\
& 0 \leq\left(\theta_{n}^{\mathrm{DA}}+\pi\right) \perp \underline{\delta}_{n}^{\mathrm{DA}} \geq 0 \quad \forall n \\
& 0 \leq\left(\pi-\theta_{n}^{\mathrm{DA}}\right) \perp \bar{\delta}_{n}^{\mathrm{DA}} \geq 0 \\
& 0 \leq\left(P_{g}^{\mathrm{G}}+r_{g \omega}^{\mathrm{G}}\right) \perp \underline{v}_{g \omega}^{\mathrm{G}} \geq 0 \\
& 0 \leq\left(\bar{P}_{g}^{\mathrm{G}}-P_{g}^{\mathrm{G}}-r_{g \omega}^{\mathrm{G}}\right) \perp \bar{v}_{g \omega}^{\mathrm{G}} \geq 0 \quad \forall g \in \mathcal{G}, \forall \omega \\
& 0 \leq\left(r_{g \omega}^{\mathrm{G}}+\bar{R}_{g}^{\mathrm{G}^{\mathrm{D}}}\right) \perp \underline{\eta}_{g \omega}^{\mathrm{G}} \geq 0 \quad \forall g \in \mathcal{G}, \forall \omega \\
& 0 \leq\left(\bar{R}_{g}^{\mathrm{G}^{\mathrm{U}}}-r_{g \omega}^{\mathrm{G}}\right) \perp \bar{\eta}_{g \omega}^{\mathrm{G}} \geq 0 \quad \forall g \in \mathcal{G}, \forall \omega \\
& 0 \leq\left(r_{q \omega}^{\mathrm{S}}-P_{q}^{\mathrm{S}}+\bar{P}_{q}^{\mathrm{S}}\right) \perp \underline{v}_{q \omega}^{\mathrm{S}} \geq 0 \quad \forall q \in \mathcal{D}^{\mathrm{S}}, \forall \omega \\
& 0 \leq\left(P_{q}^{\mathrm{S}}-r_{q \omega}^{\mathrm{S}}\right) \perp \bar{v}_{q \omega}^{\mathrm{S}} \geq 0 \quad \forall q \in \mathcal{D}^{\mathrm{S}}, \forall \omega \\
& 0 \leq\left(r_{q \omega}^{\mathrm{S}}+\bar{R}_{q}^{\mathrm{S}^{\mathrm{D}}}\right) \perp \underline{\eta}_{q \omega}^{\mathrm{S}} \geq 0 \quad \forall q \in \mathcal{D}^{\mathrm{S}}, \forall \omega \\
& 0 \leq\left(\bar{R}_{q}^{\mathrm{S}^{\mathrm{U}}}-r_{q \omega}^{\mathrm{S}}\right) \perp \bar{\eta}_{q \omega}^{\mathrm{S}} \geq 0 \quad \forall q \in \mathcal{D}^{\mathrm{S}}, \forall \omega \\
& 0 \leq\left(r_{l \omega}^{\mathrm{C}}-P_{l}^{\mathrm{C}}+\bar{P}_{l}^{\mathrm{C}}\right) \perp \underline{v}_{l \omega}^{\mathrm{C}} \geq 0 \quad \forall l \in \mathcal{D}^{\mathrm{C}}, \forall \omega \\
& 0 \leq\left(P_{l}^{\mathrm{C}}-r_{l \omega}^{\mathrm{C}}\right) \perp \bar{v}_{l \omega}^{\mathrm{C}} \geq 0 \\
& \forall l \in \mathcal{D}^{\mathrm{C}}, \forall \omega \\
& 0 \leq\left(r_{l \omega}^{\mathrm{C}}+\bar{R}_{l}^{\mathrm{C}^{\mathrm{D}}}\right) \perp \underline{\eta}_{l \omega}^{\mathrm{C}} \geq 0 \quad \forall l \in \mathcal{D}^{\mathrm{C}}, \forall \omega \\
& 0 \leq\left(\bar{R}_{l}^{\mathrm{C}^{\mathrm{U}}}-r_{l \omega}^{\mathrm{C}}\right) \perp \bar{\eta}_{l \omega}^{\mathrm{C}} \geq 0 \quad \forall l \in \mathcal{D}^{\mathrm{C}}, \forall \omega \\
& 0 \leq p_{l \omega}^{\text {Shed }} \perp \underline{\eta}_{l \omega}^{\text {Shed }} \geq 0 \quad \forall l \in \mathcal{D}^{\mathrm{C}}, \forall \omega \\
& 0 \leq\left(P_{l}^{\mathrm{C}}-r_{l \omega}^{\mathrm{C}}-p_{l \omega}^{\mathrm{Shed}}\right) \perp \bar{\eta}_{l \omega}^{\mathrm{Shed}} \geq 0 \quad \forall l \in \mathcal{D}^{\mathrm{C}}, \forall \omega \\
& 0 \leq w_{k \omega}^{\text {Spill }} \perp \underline{\eta}_{k \omega}^{\mathrm{W}} \geq 0 \quad \forall k \in \mathcal{K}, \forall \omega \\
& 0 \leq\left(W_{k \omega}^{\text {act }}-w_{k \omega}^{\text {Spill }}\right) \perp \bar{\eta}_{k \omega}^{\mathrm{W}} \geq 0 \quad \forall k \in \mathcal{K}, \forall \omega \\
& 0 \leq\left[F_{n m}-S_{n m}\left(\theta_{n \omega}^{\mathrm{B}}-\theta_{m \omega}^{\mathrm{B}}\right)\right] \perp \zeta_{n m \omega}^{\mathrm{B}} \geq 0 \\
& \forall n, \forall m \in \Psi_{n}, \forall \omega(4 \mathrm{o}) \\
& 0 \leq\left(\theta_{n \omega}^{\mathrm{B}}+\pi\right) \perp \underline{\delta}_{n \omega}^{\mathrm{B}} \geq 0 \quad \forall n, \forall \omega \\
& 0 \leq\left(\pi-\theta_{n \omega}^{\mathrm{B}}\right) \perp \bar{\delta}_{n \omega}^{\mathrm{B}} \geq 0 \quad \forall n, \forall \omega \text {. }
\end{aligned}
$$

Constraint ( $3 b$ ) contains the only upper-level constraint and the equalities included in the LL problem (2). Equalities (3c)-(3m) and the complementarity conditions $(3 n)-(4 q)$ are the KKT optimality conditions of the LL problem (2).

\section{G. MPEC Linearization}

The MPEC (3)-(4) above is nonlinear due to complementarity conditions (3n)-(4q) and the bilinear term 
$-\sum_{q \in \mathcal{D}^{\mathrm{S}}}\left[P_{q}^{\mathrm{S}} \alpha_{n: q \in \mathcal{D}_{n}^{\mathrm{S}}}^{\mathrm{DA}}-\sum_{\omega} r_{q \omega}^{\mathrm{S}} \alpha_{\left(n: q \in \mathcal{D}_{n}^{\mathrm{S}}\right) \omega}^{B}\right]$ in the objective function (1a), denoted below as $\Gamma$. The strong duality equality is utilized to substitute the bilinear term $\Gamma$ by an exactly equivalent linear term by the following step-by-step approach [15]:

1) The strong duality equality corresponding to the LL problem (2) is obtained.

2) The complementarity conditions (3s) and (4c)-(4f) render the following equalities:

$$
\begin{aligned}
\sum_{q \in D^{\mathrm{S}}} \bar{P}_{q}^{\mathrm{S}} \bar{\mu}_{q}^{\mathrm{S}} & =\sum_{q \in D^{\mathrm{S}}} P_{q}^{\mathrm{S}} \bar{\mu}_{q}^{\mathrm{S}} \\
\sum_{\left(q \in D^{\mathrm{S}}\right) \omega} \bar{P}_{q}^{\mathrm{S}} \underline{v}_{q \omega}^{\mathrm{S}} & =\sum_{\left(q \in D^{\mathrm{S}}\right) \omega} P_{q}^{\mathrm{S}} \underline{v}_{q \omega}^{\mathrm{S}}-\sum_{\left(q \in D^{\mathrm{S}}\right) \omega} r_{q \omega}^{\mathrm{S}} \underline{v}_{q \omega}^{\mathrm{S}} \\
\sum_{\left(q \in D^{\mathrm{S}}\right) \omega} P_{q}^{\mathrm{S}} \bar{v}_{q \omega}^{\mathrm{S}} & =\sum_{\left(q \in D^{\mathrm{S}}\right) \omega} r_{q \omega}^{\mathrm{S}} \bar{v}_{q \omega}^{\mathrm{S}} \\
\sum_{\left(q \in D^{\mathrm{S}}\right) \omega} \bar{R}_{q}^{\mathrm{S}^{\mathrm{D}}} \underline{\eta}_{q \omega}^{\mathrm{S}} & =-\sum_{\left(q \in D^{\mathrm{S}}\right) \omega} r_{q \omega}^{\mathrm{S}} \underline{\eta}_{q \omega}^{\mathrm{S}} \\
\sum_{\left(q \in D^{\mathrm{S}}\right) \omega} \bar{R}_{q}^{\mathrm{S}^{\mathrm{U}}} \bar{\eta}_{q \omega}^{\mathrm{S}} & =\sum_{\left(q \in D^{\mathrm{S}}\right) \omega} r_{q \omega}^{\mathrm{S}} \bar{\eta}_{q \omega}^{\mathrm{S}} .
\end{aligned}
$$

3) The equalities (5) are substituted in the strong duality equality. Specifically, the left-hand side terms in (5) are substituted with the corresponding right-hand side terms.

4) KKT equalities (3g) and (3h) are multiplied by $P_{q}^{\mathrm{S}}$ and $r_{q \omega}^{\mathrm{S}}$, respectively; then the resulting equalities are added up, which renders equality (6) below:

$$
\begin{gathered}
-\sum_{q \in D^{\mathrm{S}}} \alpha_{\left(n: q \in D_{n}^{\mathrm{S}}\right)}^{\mathrm{DA}} P_{q}^{\mathrm{S}}+\sum_{\left(q \in D^{\mathrm{S}}\right) \omega} \alpha_{\left(n: q \in D_{n}^{\mathrm{S}}\right) \omega}^{\mathrm{B}} r_{q \omega}^{\mathrm{S}}= \\
-\sum_{q \in D^{\mathrm{S}}}\left(B_{q}^{\mathrm{S}} P_{q}^{\mathrm{S}}+\underline{\mu}_{q}^{\mathrm{S}} P_{q}^{\mathrm{S}}-\bar{\mu}_{q}^{\mathrm{S}} P_{q}^{\mathrm{S}}\right) \\
+\sum_{\left(q \in D^{\mathrm{S}}\right) \omega}\left(\underline{v}_{q \omega}^{\mathrm{S}} P_{q}^{\mathrm{S}}-\bar{v}_{q \omega}^{\mathrm{S}} P_{q}^{\mathrm{S}}+\phi_{\omega} U_{q}^{\mathrm{S}} r_{q \omega}^{\mathrm{S}}-\underline{v}_{q \omega}^{\mathrm{S}} r_{q \omega}^{\mathrm{S}}\right. \\
\left.\quad+\bar{v}_{q \omega}^{\mathrm{S}} r_{q \omega}^{\mathrm{S}}-\underline{\eta}_{q \omega}^{\mathrm{S}} r_{q \omega}^{\mathrm{S}}+\bar{\eta}_{q \omega}^{\mathrm{S}} r_{q \omega}^{\mathrm{S}}\right) .
\end{gathered}
$$

5) By substituting equality (6) in the strong duality equality obtained in step 3, the bilinear term can be replaced by the exact linear equivalent $\Gamma$ as follows:

$$
\begin{aligned}
\Gamma & =-\sum_{\omega} \phi_{\omega}\left\{\sum_{g \in \mathcal{G}} O_{g}\left(P_{g}^{\mathrm{G}}+r_{g \omega}^{\mathrm{G}}\right)\right\}-\sum_{g \in \mathcal{G}} \bar{P}_{g}^{\mathrm{G}} \bar{\mu}_{g}^{\mathrm{G}} \\
& -\sum_{(g \in \mathcal{G}) \omega}\left(\bar{P}_{g}^{\mathrm{G}} \bar{v}_{g \omega}^{\mathrm{G}}+\bar{R}_{g}^{\mathrm{G}^{\mathrm{D}}} \underline{\eta}_{g \omega}^{\mathrm{G}}+\bar{R}_{g}^{\mathrm{G}^{\mathrm{U}}} \bar{\eta}_{g \omega}^{\mathrm{G}}\right) \\
& +\sum_{\omega} \phi_{\omega}\left\{\sum_{l \in \mathcal{D}^{\mathrm{C}}}\left[U_{l}^{\mathrm{C}}\left(P_{l}^{\mathrm{C}}-r_{l \omega}^{\mathrm{C}}\right)-V_{l} p_{l \omega}^{\mathrm{Shed}}\right]\right\}-\sum_{l \in \mathcal{D}^{\mathrm{C}}} \bar{P}_{l}^{\mathrm{C}} \bar{\mu}_{l}^{\mathrm{C}} \\
- & \sum_{\left(l \in \mathcal{D}^{\mathrm{C}}\right) \omega}\left(\bar{P}_{l}^{\mathrm{C}} \underline{v}_{l \omega}^{\mathrm{C}}+\bar{R}_{l}^{\mathrm{C}^{\mathrm{D}}} \underline{\eta}_{l \omega}^{\mathrm{C}}+\bar{R}_{l}^{\mathrm{C}^{\mathrm{U}}} \bar{\eta}_{l \omega}^{\mathrm{C}}\right) \\
- & \sum_{n\left(m \in \Psi_{n}\right)} F_{n m} \zeta_{n m}^{\mathrm{DA}}-\sum_{n} \pi\left(\underline{\delta}_{n}^{\mathrm{DA}}+\bar{\delta}_{n}^{\mathrm{DA}}\right)-\sum_{k \in \mathcal{K}} \bar{W}_{k} \bar{\mu}_{k}^{\mathrm{W}} \\
- & \sum_{(k \in \mathcal{K}) \omega} W_{k \omega}^{\mathrm{act}}\left[\bar{\eta}_{k \omega}^{W}+\alpha_{\left(n: k \in \mathcal{K}_{n}\right) \omega}^{\mathrm{B}}\right]
\end{aligned}
$$

TABLE I

Data for Generating Units (Single-Area Case Study)

\begin{tabular}{|c|c|c|c|c|c|}
\hline $\begin{array}{c}\text { Generating } \\
\text { unit } \\
(\mathrm{g})\end{array}$ & Type & $\begin{array}{c}\text { Unit } \\
\text { capacity } \\
(\mathrm{MW})\end{array}$ & $\begin{array}{c}\text { Marginal } \\
\text { cost } \\
(\mathbf{M W h})\end{array}$ & $\begin{array}{c}\text { Maximum } \\
\text { up and down reserve } \\
\text { capacity (MW) }\end{array}$ & $\begin{array}{c}\text { Location } \\
\text { (bus) }\end{array}$ \\
\hline G1 & Base & 40 & 15.00 & 0 & 1 \\
\hline G2 & Base & 152 & 12.46 & 0 & 1 \\
\hline G3 & Base & 40 & 15.00 & 0 & 2 \\
\hline G4,G5 & Base & 76 & 12.46 & 0 & 2 \\
\hline G6-G8 & Base & 100 & 16.00 & 0 & 7 \\
\hline G9-G11 & Base & 197 & 13.58 & 0 & 13 \\
\hline G12-G16 & Peak & 12 & 18.57 & 2.4 & 15 \\
\hline G17 & Intermediate & 155 & 11.09 & 15.5 & 15 \\
\hline G18 & Intermediate & 155 & 11.09 & 15.5 & 16 \\
\hline G19 & Base & 400 & 12.00 & 0 & 18 \\
\hline G20 & Base & 400 & 12.00 & 0 & 21 \\
\hline G21-G26 & Peak & 50 & 0.00 & 10 & 22 \\
\hline G27,G28 & Intermediate & 155 & 11.09 & 15.5 & 23 \\
\hline G29 & Intermediate & 100 & 16.75 & 10 & 23 \\
\hline G30 & Intermediate & 100 & 17.25 & 10 & 23 \\
\hline G31 & Intermediate & 100 & 17.75 & 10 & 23 \\
\hline G32 & Intermediate & 50 & 18.10 & 5 & 23 \\
\hline
\end{tabular}

$-\sum_{n\left(m \in \Psi_{n}\right) \omega} F_{n m} \zeta_{n m \omega}^{B}-\sum_{n \omega} \pi\left(\underline{\delta}_{n \omega}^{\mathrm{B}}+\bar{\delta}_{n \omega}^{\mathrm{B}}\right)$.

For more on the principles of this approach see [15]. In addition, each complementarity condition (3n)-(4q) of the form $0 \leq a \perp$ $b \geq 0$ is equivalent to the set of mixed-integer linear conditions $a \geq 0, b \geq 0, a \leq u M, b \leq(1-u) M$, where $u$ is an auxiliary binary variable, and $M$ is a large enough positive constant [24].

\section{NumericAl Results}

In this section, the one-area and the three-area IEEE reliability test systems (IEEE RTS-24 and RTS-72) [25] are used to illustrate different features and outcomes of the strategic consumer's bidding and the practical functioning and consistency of the proposed model.

\section{A. Illustrative Case Study}

1) Data: The data for the illustrative case study (single-area IEEE RTS) is presented in Tables I and II. Table I presents generating units' data and location. Maximum reserve capacities of base, intermediate and peak units are assumed $0 \%, 10 \%$ and $20 \%$ of their capacity, respectively.

Data for strategic and competitive loads including their type (responsive, non-responsive and semi-responsive), and location are given in Table II. The case study has 17 loads; loads Q1 to Q7 and L1 to L10 are owned by the strategic and competitive consumers, respectively. Same as generating units, maximum reserve capacities of loads differ based on their type. Maximum reserve capacities for non-responsive, semi-responsive and responsive loads are assumed $0 \%, 7.5 \%$ and $15 \%$ of their maximum demand, respectively. Total maximum demand of the strategic consumer is $1,064.88 \mathrm{MW}$, which is $36.63 \%$ of total maximum demand of all loads (2,907 MW). Note that maximum demand of each load is identical to that in [25] raised by $2 \%$. VOLL for competitive loads is assumed to be $\$ 10,000 / \mathrm{MWh}$. Maximum energy bid price to be submitted by the strategic consumer is $\$ 180 / \mathrm{MWh}$. For simplicity and to make the findings more intuitive, the capacity of all the transmission lines are increased to $600 \mathrm{MW}$, so transmission 
TABLE II

DATA FOR LOADS OF THE STRATEGIC AND COMPETITIVE CONSUMERS

\begin{tabular}{|c|c|c|c|c|c|}
\hline Load & Type & $\begin{array}{c}\text { Maximum } \\
\text { demand } \\
(\mathrm{MW})\end{array}$ & $\begin{array}{c}\text { Marginal } \\
\text { utility } \\
(\$ / \mathrm{MWh})\end{array}$ & $\begin{array}{c}\text { Maximum } \\
\text { and down reserve } \\
\text { capacity }(\mathrm{MW})\end{array}$ & $\begin{array}{c}\text { Location } \\
\text { (bus) }\end{array}$ \\
\hline Q1 & Semi-responsive & 110.16 & 23.5 & 8.26 & 1 \\
\hline Q2 & Responsive & 98.94 & 20.0 & 14.84 & 2 \\
\hline Q3 & Non-responsive & 183.60 & 26.5 & 0.00 & 3 \\
\hline Q4 & Non-responsive & 75.48 & 27.3 & 0.00 & 4 \\
\hline Q5 & Responsive & 72.42 & 19.0 & 10.86 & 5 \\
\hline Q6 & Responsive & 339.66 & 21.3 & 50.95 & 18 \\
\hline Q7 & Semi-responsive & 184.62 & 22.3 & 13.85 & 19 \\
\hline \hline L1 & Non-responsive & 138.72 & 27.3 & 0.00 & 6 \\
\hline L2 & Non-responsive & 127.50 & 29.0 & 0.00 & 7 \\
\hline L3 & Semi-responsive & 174.42 & 25.0 & 13.08 & 8 \\
\hline L4 & Non-responsive & 178.50 & 27.5 & 0.00 & 9 \\
\hline L5 & Responsive & 198.90 & 19.0 & 29.84 & 10 \\
\hline L6 & Responsive & 270.30 & 20.0 & 40.55 & 13 \\
\hline L7 & Responsive & 197.88 & 21.0 & 29.68 & 14 \\
\hline L8 & Non-responsive & 323.34 & 28.5 & 0.00 & 15 \\
\hline L9 & Non-responsive & 102 & 27.0 & 0.00 & 16 \\
\hline L10 & Responsive & 130.56 & 22.0 & 19.58 & 20 \\
\hline
\end{tabular}

TABLE III

DATA FOR Wind POWER Production Scenarios

\begin{tabular}{|r|c|c|c||c|c|c|c|}
\hline$\omega$ & $\phi_{\omega}$ & $W_{(k=1) \omega}^{\text {act }}$ & $W_{(k=2) \omega}^{\text {act }}$ & $\omega$ & $\phi_{\omega}$ & $W_{(k=1) \omega}^{\text {act }}$ & $W_{(k=2) \omega}^{\text {act }}$ \\
\hline 1 & 0.015 & 200 & 170.00 & 16 & 0.050 & 119.6 & 78.0 \\
\hline 2 & 0.030 & 162 & 137.00 & 17 & 0.035 & 110.4 & 72.0 \\
\hline 3 & 0.040 & 153 & 130.05 & 18 & 0.030 & 92.0 & 60.0 \\
\hline 4 & 0.040 & 144 & 122.40 & 19 & 0.025 & 55.2 & 36.0 \\
\hline 5 & 0.050 & 135 & 114.75 & 20 & 0.020 & 46.0 & 30.0 \\
\hline 6 & 0.050 & 126 & 107.10 & 21 & 0.015 & 228.0 & 264.0 \\
\hline 7 & 0.030 & 108 & 91.80 & 22 & 0.030 & 209.0 & 242.0 \\
\hline 8 & 0.030 & 90 & 76.50 & 23 & 0.040 & 180.5 & 209.0 \\
\hline 9 & 0.030 & 81 & 68.50 & 24 & 0.040 & 152.0 & 176.0 \\
\hline 10 & 0.015 & 54 & 45.90 & 25 & 0.050 & 133.0 & 154.0 \\
\hline 11 & 0.020 & 184 & 120.00 & 26 & 0.050 & 114.0 & 132.0 \\
\hline 12 & 0.020 & 165.6 & 108.00 & 27 & 0.030 & 95.0 & 110.0 \\
\hline 13 & 0.040 & 147.2 & 96.00 & 28 & 0.030 & 76.0 & 88.0 \\
\hline 14 & 0.040 & 138 & 90.00 & 29 & 0.030 & 57.0 & 66.0 \\
\hline 15 & 0.050 & 128.8 & 84.00 & 30 & 0.025 & 38.0 & 44.0 \\
\hline
\end{tabular}

constraints are non-binding. However, the impact of transmission constraints on bidding strategy of the strategic consumer is studied later through a congested case.

Table III presents data for the two wind farms $\mathrm{K} 1$ and $\mathrm{K} 2$ of the single-area case study, including their production under different scenarios and probability of such scenarios. Wind farms $\mathrm{K} 1$ and $\mathrm{K} 2$ are located at buses 3 and 14, and their installed capacities are assumed to be $228 \mathrm{MW}$ and $264 \mathrm{MW}$, respectively. Expected value and expected standard deviation of wind power production of farm K1 are 124.8 MW and 41.62 MW. For wind farm K2, expected value and expected standard deviation are 111.54 MW and 50.03 MW, respectively. Accordingly, the wind power production of farm $\mathrm{K} 2$ has higher volatility than that of farm K1. The case corresponding to Table I to Table III is referred as "Base Case".

The difference between the four cases considered are presented in Table IV. The cases differ in the participation of loads in reserve provision, their reserve deployment capacity, and characteristics of the wind farms.

2) Competitive Versus Strategic Bidding: In this section, Case 1 (which is our Base Case) is studied to compare the
TABLE IV

Characteristics of Case Studies

\begin{tabular}{|c|c|c|c|c|c|c|c|c|}
\hline Cases & $\begin{array}{c}\text { Reserve } \\
\text { provision } \\
\text { by the } \\
\text { demand-side }\end{array}$ & \multicolumn{2}{|c|}{$\begin{array}{c}\text { Reserve } \\
\text { capacity of loads } \\
\text { as \% of } \\
\text { maximum demand }\end{array}$} & \multicolumn{2}{|c|}{$\begin{array}{c}\text { Expected } \\
\text { standard deviation } \\
\text { of production of } \\
\text { wind farms (MW) }\end{array}$} & \multicolumn{2}{|c|}{$\begin{array}{c}\text { Expected } \\
\text { production } \\
\text { of } \\
\text { wind farms (MW) }\end{array}$} \\
\cline { 2 - 5 } & $\mathrm{NR}^{*}$ & $\mathrm{SR}^{*}$ & $\mathrm{R}^{*}$ & $\mathrm{~K} 1$ & $\mathrm{~K} 2$ & $\mathrm{~K} 1$ & $\mathrm{~K} 2$ \\
\hline Case 1 & $\checkmark$ & 0.0 & 7.5 & 15 & & & & \\
\hline Case 2 & -- & 0.0 & 0.0 & 0.0 & 41.62 & 50.03 & 124.80 & 111.54 \\
\hline Case 3 & $\checkmark$ & 0.0 & 5.5 & 13 & & & & \\
\hline Case 4 & $\checkmark$ & 0.0 & 7.5 & 15 & 27.92 & 32.53 & & \\
\hline
\end{tabular}

outcomes of the strategic consumer's competitive and strategic behavior. The result are presented in Table V. Rows two and three of Table $\mathrm{V}$ give the values of dispatched wind in the DAM and the expected wind power spillage, respectively. The fourth row presents the strategic consumer's energy bid price for the DAM. Day-ahead LMPs and expected balancing LMPs are also given in rows five and six. The expected value of the strategic consumer's not-supplied energy is presented in the seventh row. Total expected utility of the strategic consumer is given in the eighth row. Rows ninth and tenth give expected utility of the strategic consumer in the DAM and the balancing stage, respectively. The eleventh and twelfth rows present the total expected utility of competitive consumers and the total expected profit of generating units, respectively. The last row shows total expected social welfare of the market. In this case, the strategic consumer has the opportunity to supply a fraction of its demand deploying down reserve in the balancing stage depending on the deployment capability of its loads. Results for Case 1 given in Table V show that:

a) LMPs are lower under the strategic demand-side (equal to $\$ 13.58 / \mathrm{MWh}$ ) as the strategic consumer underbids its demand in the DAM. Although by underbidding the demand the strategic consumer reduces its utility from supplying energy (i.e., expected unsupplied energy increases) this cost is more than offset by the increase in utility from lower DAM's LMPs. The net effect is that the expected utility of the strategic consumer in the DAM is $\$ 1,128$ higher when it behaves strategically (row 9).

b) A fraction of the strategic consumer's demand is not scheduled in the DAM under strategic bidding. However, part of the unscheduled demand is supplied in the balancing stage through down-reserve deployment so it is expected the consumer will only have $46.14 \mathrm{MWh}$ of expected energy not supplied.

c) The strategic behavior of the large consumer reduces the scheduled wind production in the DAM and hence increases both the availability of free wind energy and the required down reserves in the balancing stage necessary in order to maximize the supply to meet its demand. As a result, its expected utility in the balancing stage increases by $\$ 140$ (row 10 ).

d) The total expected utility of the competitive consumers is higher in the strategic case. Indeed, although the competitive consumers behave as price-takers, they free-ride on the strategic consumer's behavior fully supplying their load at lower LMPs relative to prices in the competitive case. Neither in the strategic nor in the competitive cases the competitive consumers have any unserved load, but in the strategic case LMPs are lower. 
TABLE V

STRATEGIC AND COMPETITIVE BIDDING RESUlts FOR CASE 1

\begin{tabular}{|l|c|c|}
\hline Result & $\begin{array}{c}\text { Strategic } \\
\text { demand-side }\end{array}$ & $\begin{array}{c}\text { Competitive } \\
\text { demand-side }\end{array}$ \\
\hline Scheduled wind power production in the DAM (MW) & 24.51 & 44.01 \\
\hline Expected wind power spillage (MW) & 1.56 & 0.68 \\
\hline Energy bid price by the strategic consumer (\$/MWh) & 13.58 & Marginal utility \\
\hline Day-ahead LMPs (\$/MWh) (Buses 1 to 24) & 13.58 & 15.00 \\
\hline Expected balancing LMPs (\$/MWh) (Buses 1 to 24) & 13.58 & 15.00 \\
\hline $\begin{array}{l}\text { Expected energy not supplied } \\
\text { of the strategic consumer (MWh) }\end{array}$ & 46.1 & 0.00 \\
\hline Total EU* of the strategic consumer (\$) & 9517 & 8249 \\
\hline Utility of the strategic consumer in the DAM (\$) & 8766 & 7638 \\
\hline EU of the strategic consumer in the balancing stage (\$) & 751 & 611 \\
\hline Total EU of all competitive consumers (\$) & 19920 & 17305 \\
\hline Total expected profit of all generating units (\$) & 7391 & 11064 \\
\hline Expected social welfare (\$) & 30818 & 39771 \\
\hline
\end{tabular}

TABLE VI

STRATEGIC BIDDING Results FOR All CASES

\begin{tabular}{|l|c|c|c|c|}
\hline Result & Case 1 & Case 2 & Case 3 & Case 4 \\
\hline $\begin{array}{l}\text { Scheduled wind power production } \\
\text { in the DAM (MW) }\end{array}$ & 24.51 & 190 & 111.258 & 95.67 \\
\hline Expected wind power spillage (MW) & 1.56 & 10.70 & 0.55 & 0.97 \\
\hline Day-ahead LMPs (\$/MWh) (Buses 1 to 24) & 13.58 & 13.58 & 13.58 & 13.58 \\
\hline $\begin{array}{l}\text { Expected energy not supplied } \\
\text { of the strategic consumer (MWh) }\end{array}$ & 46.1 & 112.0 & 51.3 & 48.8 \\
\hline EU* of the strategic consumer in the balancing stage (\$) & 751 & 0 & 623.44 & 746 \\
\hline Total EU of the strategic consumer (\$) & 9517 & 9120 & 9487 & 9500 \\
\hline Expected social welfare (\$) & 30818 & 29994 & 30721 & 30958 \\
\hline
\end{tabular}

e) The strategic behavior of the large consumer has detrimental impacts on other market outcomes relative to the competitive case, including the total expected profit of generating units (\$3673 lower) and expected social welfare of the market (\$8953 lower).

3) Strategic Bidding Outcomes in Different Cases: This section highlights factors impacting the strategic consumer's behavior and its outcomes by comparing Case 2, Case 3, and Case 4 to Case 1, all presented in Table VI. Comparison of the results for the first three cases (Case 1, Case 2, and Case 3) highlights the effects of increased capability of reserve provision . Note that Case 3 is intermediate between Case 1 (maximum reserve provision capability) and Case 2 (no reserve provision capability). Furthermore, comparison of Case 1 and Case 4 explores the effects of increased wind power production variability, under similar reserve provision capability.

Rows 2 and 3 present the scheduled wind production in the DAM and expected wind spillage, respectively. Day-ahead LMPs are also given in row 4 . Row 5 presents the expected value of the strategic consumer's not-supplied energy. Rows 6 and 7 present the expected utility of the strategic consumer in the balancing stage and in total, respectively. The last row shows the expected value of the total social welfare of the market.

The following conclusions can be drawn from comparing the results of Case 2, where DAM is the strategic consumer's sole option for supplying its demand, to Case 1:

a) As the strategic consumer is banned from reserve provision in Case 2, a larger amount of wind energy is scheduled in the DAM.

b) In Case 2, the only available tool to the strategic consumer for gaming is cutting a part of its demand in the DAM. As a result, the expected value of the strategic consumer's not-supplied energy increases by 65.9 MWh (112-46.1) in Case 2 so that its total utility is reduced by $\$ 397$ (i.e., \$9517-\$9120).

c) Reserve deployment significantly contributes to the large consumer's market power and its influence on market outcomes.

Another factor affecting the strategic consumer's strategic behavior (investigated using Case 3) is its reserve deployment capacity. Comparing the results of this case with Case 1 reveals that the reduction in the strategic consumer's reserve deployment capacity increases the scheduled wind production in the DAM. This reduces the demand for down-reserve deployment in the balancing stage, and forces the strategic consumer to accept a higher expected value of energy not supplied in order to achieve the same LMPs as in Case 1. Therefore, its expected total utility is lower in Case 3. Similar results are obtained in Case 4. In Case 4, production of the wind farms have lower expected standard deviation (as a measure of variability) than Case 1 , while the expected production values are the same. The lower variability reduces demand for reserve deployment so that a smaller fraction of reserve's demand is supplied by the strategic consumer, and hence its expected utility decreases with respect to Case 1.

4) Strategic Bidding in a Congested Network: In this section, Case 1 (the Base Case) is modified to investigate the reactions of the strategic consumer to congestion in the network and its impacts on market outcomes. To create congestion in Case 1, the test case (IEEE RTS-24) is divided into two subareas, North and South, where the North subarea includes buses 14-24, and the South subarea buses 1-13. The two subareas are interconnected through four branches: 1) from bus 24 to bus 3,2 ) from bus 14 to bus 11,3 ) from bus 23 to bus 12 , and 4 ) from bus 23 to bus 13 . The available transmission capacity (ATC) of the interconnection between the subareas is $500 \mathrm{MW}$. To better highlight the impact of congestion on the bidding behavior of the strategic consumer and its market outcomes, the strategic bidding results in congested conditions are compared to results obtained under strategic bidding when there is no congestion (i.e., Case 1) in Table VII. Note that the order of reported results in rows of Table VII are identical to the order of reported results in Table V. The following observations can be made from the results presented in Table VII:

a) Due to transmission congestion the LMPs are different in the two subareas, with the LMP in the North being lower than in the South. Moreover, the LMP of the North in the congested case is lower than that in the uncongested case. Consequently, under transmission congestion, the expected utility of the strategic consumer is higher than under no congestion, though the expected value of its notsupplied energy is higher than in the uncongested case.

b) All the expected not-supplied energy in the congested case corresponds to strategic loads located in the South subarea where the majority of strategic loads are Located. This is because having not supplied load in the north subarea further exacerbates the congestion and increases the need for generation from more expensive units in the South to alleviate congestion, which would further increase the LMPs.

c) The general conclusion to be made is that the bidding behavior of the strategic consumer in a congested net- 
work and its market outcomes significantly depend on the topology of the grid (location of generating units and loads), and the subareas resulting from congestion.

d) In some cases, it may happen that the strategic consumer forces congestion to increase its expected utility.

\section{B. Large-Scale Case Study}

In this section, the strategic bidding model is examined on the three-area test system (IEEE RTS-72) [25] for a 24-hour time period (running the model individually for each hour). Assumptions on conventional generating units, loads (strategic and nonstrategic) and intra-area transmission lines of the three areas are identical and equal to those in the previous subsection. Transmission constraints of the lines interconnecting the three areas are chosen to be non-binding. Three wind farms K1, K2, and $\mathrm{K} 3$ are assumed to be located at bus 3 of areas 1, 2, and 3, respectively. The uncertainty on wind generation is represented with a total of 30 scenarios of hourly wind power production from each farm. Note that instead of discretizing the uncertainty set through scenarios in order to reduce the infinite-dimensional problem to a finite dimensional one, it would be possible to choose a set of functions that serve as a basis for the uncertainty set. The scenarios used for in-sample simulations are constructed based on the data for the first 500 days of the available 1000 data points, on aggregated hourly power production from wind farms in Belgium [26] and Ireland [27] (so there are 500 data points for the production of each wind farm in each hour). From the data, for each of the 24 hours (including off-peak hours t1 to t11, shoulder hours t12 to t17 and t22 to t24, and peak hours t18 to t21), we divided the range of observed values into 5 equal-length intervals corresponding to five different possible states of wind power generation: very low, low, medium, high and very high. The probabilities of each of the 5 states were calculated as the frequency of each state observed in the sample. Because wind power production from the three farms is assumed to be independent of each other, for each hour there are $5^{3}=125$ possible scenarios of aggregated wind power production. In order to maintain computational tractability the set of 125 possible scenarios is reduced to a set of 30 chosen using the method presented in [28].

Although reducing the set of scenarios to 30 may fail to represent all the possible conditions of wind power generation, any misrepresentation of the uncertainty does not have an impact in the in-sample analysis we conduct or its results. This is because the same 30 scenarios represent the information used by the strategic consumer to design its bid (and by the market operator to clear the DAM) are also assumed to be representative of the wind production observed in real time and the corresponding clearing of the balancing stage. However this use of scenarios implicitly assumes that the strategic consumer has a very good idea of what future wind power production may be. In order to explore the robustness of strategic consumer's bids to its imperfect characterization of the uncertainty on wind power production we conduct an "out-of-sample" simulation. That is, we look at a case where the strategic consumer has a less accurate characterization of the uncertainty and rather than constructing scenarios from the same 500 days of available historical data (i.e., days 1 to 500), has information about only the second half of the data (i.e., days 501 to 1000). Hence, for the out-of-sample results, the expected outcomes are calculated over a different set of scenarios than those used as input to the model. In other
TABLE VII

Strategic Bidding Results in CONGESTed AND NORMAL CONDITIONS FOR CASE 1

\begin{tabular}{|l|c|c|}
\hline Result & $\begin{array}{c}\text { Normal } \\
\text { condition }\end{array}$ & $\begin{array}{c}\text { Congested } \\
\text { condition }\end{array}$ \\
\hline \hline Scheduled wind power production in the DAM (MW) & 24.51 & 72.17 \\
\hline Expected wind power spillage (MW) & 1.56 & 0.53 \\
\hline $\begin{array}{l}\text { Energy bid price by the strategic } \\
\text { consumer (\$MWh) (South, North) }\end{array}$ & $13.58,13.58$ & $13.58,12.00$ \\
\hline Day-ahead LMPs (\$/MWh) (South, North) & $13.58,13.58$ & $13.58,12.00$ \\
\hline Expected balancing LMPs (\$MWh) (South, North) & $13.58,13.58$ & $13.58,12.00$ \\
\hline $\begin{array}{l}\text { Expected energy not supplied } \\
\text { of the strategic consumer (MWh) }\end{array}$ & 46.1 & 105.9 \\
\hline Total EU* of the strategic consumer (\$) & 9517 & 9991 \\
\hline Utility of the strategic consumer in the DAM (\$) & 8766 & 9198 \\
\hline EU of the strategic consumer in the balancing stage (\$) & 751 & 793 \\
\hline Total EU of all competitive consumers (\$) & 19920 & 21101 \\
\hline Total expected profit of all generating units (\$) & 7391 & 4646 \\
\hline Expected social welfare (\$) & 30818 & 29943 \\
\hline
\end{tabular}

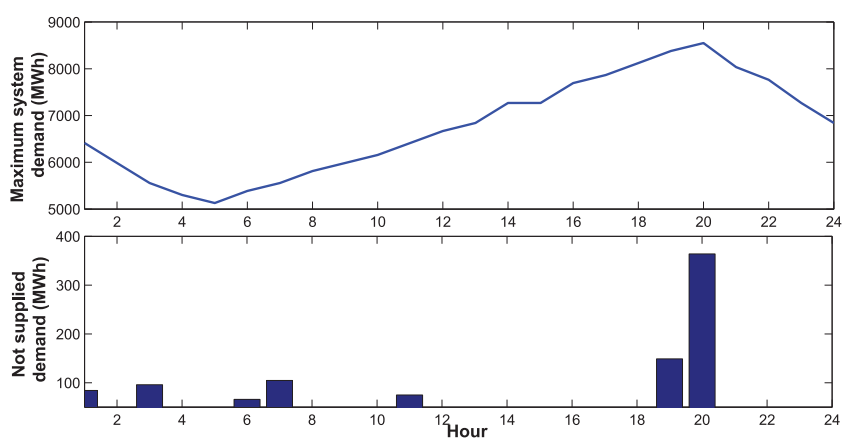

Fig. 1. Maximum system demand and hourly not-supplied demand of the strategic consumer for the three area system obtained in-sample.

words, for the in-sample results, it is assumed that the strategic consumer has complete information about the distribution function of wind power production identical to the operator of the market, when generating the set of scenarios. However, for the out-of-sample results, the strategic consumer has incomplete information and the utilized distribution function is constructed using a different subset of the data available to the market operator. In a sense, out-of-sample simulation evaluates the quality of the generated scenarios for production of the wind farms and whether or not they appropriately capture the uncertainty of wind power production from the strategic consumer's perspective.

Figs. 1 and 2 illustrate in-sample results for the strategic and competitive bidding of the strategic consumer. Note that the maximum system demand depicted in Fig. 1 refers to the possible maximum electricity demand in the system, which is equal to the sum of the demand from all strategic and competitive loads when the price is zero (i.e., the demand curve's intercept with the vertical axis). Wind spillage ratio in Fig. 2 refers to the ratio of expected wind spillage to the expected wind power production over the set of scenarios. As seen, the strategic consumer's strategic bidding lowers the LMPs during off-peak hours (t1, t3, t6, and t8), shoulder hours (t12) and peak hours (t19 and t20). As a result, expected total daily utility of the strategic consumer increases by $15,009(2.65 \%)$ with strategic bidding. However, $938 \mathrm{MWh}$, equivalent to $4.68 \%$ of its maximum daily demand, are unsupplied. 


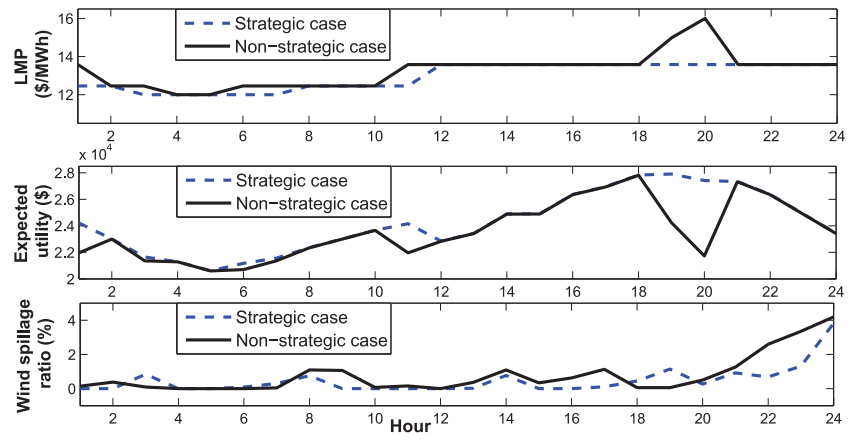

Fig. 2. LMPs, expected utility of the strategic consumer and wind spillage ratio for the three area system obtained in-sample.

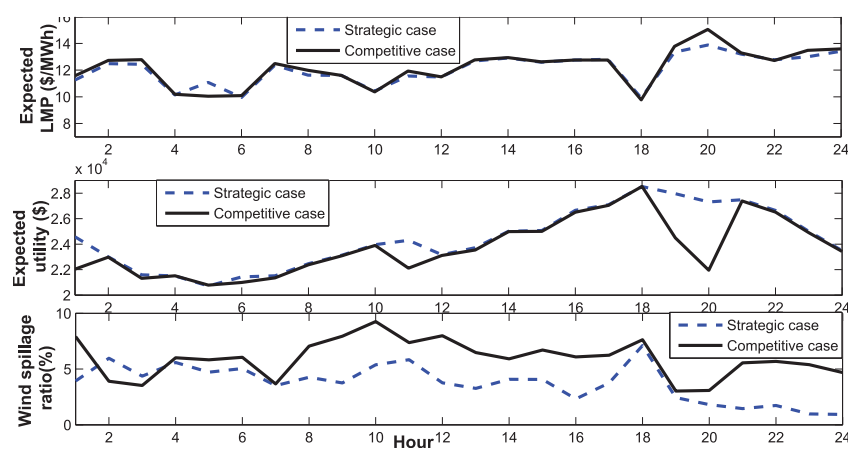

Fig. 3. Expected balancing LMP, expected utility of the strategic consumer, and wind spillage ratio of the three area system obtained out-of-sample.

Fig. 3 shows the out-of-sample results of the strategic and competitive bidding. Wind spillage ratio in Fig. 3 refers to the ratio of the expected wind spillage to the expected wind power production over the set of unseen wind power production samples. As seen, the calculated out-of-sample results for competitive and strategic biding cases follow the patterns similar to the in-sample results. For instance, total expected utility of the strategic consumer from strategic bidding is $\$ 15,499$ higher $(\% 2.72)$ than that obtained in the competitive case. This increase in the out-of-sample expected utility from strategic bidding is due to a higher realization of wind power production than what was expected by the strategic consumer from its uncertainty characterization. Additionally, under the strategic case, the expected LMPs in the balancing stage are lower than those obtained in the competitive case except during time periods $\mathrm{t} 5, \mathrm{t} 10, \mathrm{t} 12$, and $\mathrm{t} 17$. These and other differences (such as those on the wind-spillage ratio) between the in-sample and out-of-sample results, stem from different characteristics of the in-sample and out-of-sample wind power production data sets. For instance, hourly average expected wind production for the in-sample data is $487 \mathrm{MW}$, which is $41 \mathrm{MW}$ lower than the hourly average out-of-sample wind power production. Higher amounts of down-reserve scheduled in the strategic case, with respect to those in the competitive case, contribute to the wind-spillage ratio differences as the strategic consumer's behavior tends to increase the demand for down-reserve deployment in the balancing stage.
TABLE VIII

RESUlts RElATED TO THE COMPUTATIONAL COMPLEXITY OF THE STRATEGIC BIDDING MODEL

\begin{tabular}{|c|c|c|c|c|}
\hline \multirow{2}{*}{ Test Case } & \multicolumn{2}{|c|}{ Number of variables } & \multirow{2}{*}{$\begin{array}{l}\text { Number of } \\
\text { constraints }\end{array}$} & \multirow{2}{*}{$\begin{array}{l}\text { CPU time } \\
\text { (Second) }\end{array}$} \\
\hline & Continuous & Binary & & \\
\hline IEEE RTS-24 & 22586 & 8688 & 24019 & 73 \\
\hline IEEE RTS-72 & 60065 & 22702 & 76262 & 11880 \\
\hline
\end{tabular}

\section{Computational Considerations}

The computational burden of the proposed model is characterized in Table VIII for the single-area (IEEE RTS-24) and the three-area (IEEE RTS-72) test cases. As shown, the CPU time for solving the illustrative case study (IEEE RTS-24) for a single time period is 73 seconds, and for the large-scale case study (IEEE RTS-72) for a 24-hour time horizon is $11,880 \mathrm{sec}-$ onds. It is worth noting that increasing the number of wind farms further increases the computational complexity of both the stochastic market clearing problem and the derivation of the strategic day-ahead bidding curves for the large consumer. This is due to the fact that adding wind farms exponentially increases the size of the set of scenarios required to characterize the uncertainty on the wind power production. This increase in the number of scenarios is matched with an increase in the number of continuous and binary decision variables. Nevertheless, there are multiple alternatives available for resolving this problem including utilizing a supercomputer, implementing decomposition and/or parallel computing techniques [29], [30], applying appropriate techniques to simplify the network [31] and reducing the number of scenarios through existing scenarioreduction techniques [28]. For all case studies, CPLEX 12.3 under GAMS [32] is used to solve the resulting MILP problem on a PC with two processors clocking at $3.3 \mathrm{GHz}$ and $4 \mathrm{~GB}$ of RAM.

\section{CONClusions AND Future Research}

The numerical results reveal that a large, price-responsive strategic consumer providing operating reserves can increase total expected utility and decrease the expected value of its energy not-supplied. The market power of this strategic consumer is enhanced in proportion of its capacity to provide operating reserves, and can significantly impact the scheduling of wind power production in the DAM, and increase the required down reserve in the balancing stage. Since this paper considers a single-hour auction, the introduced model underestimates market power of the strategic consumer as its load-shifting capability is ignored. Also, it is worth noting that the outcomes of this study are obtained assuming the large consumer has full information about the network, demand bids, supply offers, and distribution function for production of the wind farms. Therefore, the calculated outcomes represent an upper bound on the extent that the strategic consumer can exercise market power. Future work will study the strategic behavior of a large consumer that benefits from energy storage and load shifting capabilities and the interaction of strategic consumers and producers.

\section{REFERENCES}

[1] J. M. Morales, A. J. Conejo, K. Liu, and J. Zhong, "Pricing electricity in pools with wind producers," IEEE Trans. Power Syst., vol. 23, no. 3, pp. 1366-1376, Aug. 2012. 
[2] G. Pritchard, G. Zakeri, and A. Philpott, "A single-settlement, energyonly electric power market or unpredictable and intermittent participants," Oper. Res., vol. 58, no. 4, pp. 1210-1219, Jul.-Aug. 2010.

[3] J. M. Morales, A. J. Conejo, H. Madsen, P. Pinson, and M. Zugno, Integrating Renewables in Electricity Markets, ser. International Series in Operations Research and Management Science. New York, NY, USA: Springer, 2013.

[4] S. Wong and J. D. Fuller, "Pricing energy and reserves using stochastic optimization in an alternative electricity market," IEEE Trans. Power Syst., vol. 22, no. 2, pp. 631-638, May 2007.

[5] J. Khazaei, G. Zakeri, and G. Pritchard, "The effects of stochastic market clearing on the cost of wind integration: A case of New Zealand electricity market," Energy Syst., vol. 5, no. 4, pp. 657-675, Dec. 2014.

[6] S. Martin, Y. Smeers, and J. A. Aguado, "A stochastic two settlement equilibrium model for electricity markets with wind generation," IEEE Trans. Power Syst., vol. 30, no. 1, pp. 233-245, Jan. 2015.

[7] S. E. Fleten and E. Pettersen, "Constructing bidding curves for a price-taking retailer in the Norwegian electricity market," IEEE Trans. Power Syst., vol. 20, no. 2, pp. 701-708, May 2005.

[8] A. B. Philpott and E. Pettersen, "Optimizing demand-side bids in dayahead electricity markets," IEEE Trans. Power Syst., vol. 21, no. 2, pp. 488-498, May 2006.

[9] D. Menniti, F. Costanzo, N. Scordino, and N. Sorrentino, "Purchasebidding strategies of an energy coalition with demand-response capabilities," IEEE Trans. Power Syst., vol. 24, no. 3, pp. 1241-1255, Aug. 2009.

[10] Y. Liu and X. Guan, "Purchase allocation and demand bidding in electric power markets," IEEE Trans. Power Syst., vol. 18, no. 1, pp. 106-112, Feb. 2003.

[11] M. Carrión, A. B. Philpott, A. J. Conejo, and J. M. Arroyo, “A stochastic programming approach to electric energy procurement for large consumers," IEEE Trans. Power Syst., vol. 22, no. 2, pp. 744-754, May 2007.

[12] K. Zare, A. J. Conejo, M. Carrión, and M. P. Moghaddam, "Multimarket energy procurement for a large consumer using a risk-aversion procedure," Elect. Power Syst. Res., vol. 80, no. 1, pp. 63-70, Jan. 2010.

[13] R. Herranz, A. M. S. Roque, J. Villar, and F. A. Campos, "Optimal demand-side bidding strategies in electricity spot markets," IEEE Trans. Power Syst., vol. 27, no. 3, pp. 1204-1213, Aug. 2012.

[14] S. J. Kazempour, A. J. Conejo, and C. Ruiz, "Strategic bidding for a large consumer," IEEE Trans. Power Syst., vol. 30, no. 2, pp. 848-855, Mar. 2015.

[15] C. Ruiz and A. J. Conejo, "Pool strategy of a producer with endogenous formation of locational marginal prices," IEEE Trans. Power Syst., vol. 24, no. 4, pp. 1855-1866, Nov. 2009.

[16] H. Mohsenian-Rad, "Coordinated price-maker operation of large energy storage units in nodal energy markets," IEEE Trans. Power Syst.

[17] F. H. Murphy and Y. Smeers, "Generation capacity expansion in imperfectly competitive restructured electricity markets," Oper. Res., vol. 53, no. 4, pp. 646-661, Jul. 2005.

[18] S. J. Kazempour, A. J. Conejo, and C. Ruiz, "Strategic generation investment using a complementarity approach," IEEE Trans. Power Syst., vol. 26, no. 2, pp. 940-948, May 2011.

[19] L. P. Garces, A. J. Conejo, R. G. Bertrand, and R. Romero, "A bilevel approach to transmission expansion planning within a market environment," IEEE Trans. Power Syst., vol. 24, no. 3, pp. 1513-1522, Aug. 2009.

[20] E. E. Sauma and S. S. Oren, "Proactive planning and valuation of transmission investment in restructured electricity markets," J. Reg. Econ., vol. 30, no. 3, pp. 261-290, Nov. 2006.

[21] G. Brown, M. Carlyle, J. Salmeron, and K. Wood, "Defending critical infrastructure," Interfaces, vol. 36, no. 6, pp. 530-544, Nov. 2006.

[22] H. Pandzic, A. J. Conejo, and I. Kuzle, "An EPEC approach to the yearly maintenance scheduling of generating units," IEEE Trans. Power Syst., vol. 28, no. 2, pp. 922-930, May 2013.

[23] H. Pandzic, A. J. Conejo, I. Kuzle, and E. Caro, "Yearly maintenance scheduling of transmission lines within a market environment," IEEE Trans. Power Syst., vol. 27, no. 1, pp. 407-415, Feb. 2012.
[24] J. Fortuny-Amat and B. McCarl, "A representation and economic interpretation of a two-level programming problem," J. Oper. Res. Soc., vol. 32, no. 9, pp. 783-792, Sep. 1981.

[25] "Relaibility system task force, the IEEE reliability test system-1996: A report prepared by the reliability test system task force of the application of probability methods subcommittee," IEEE Trans. Power Syst., vol. 14, no. 3, pp. 1010-1020, Aug. 1999.

[26] Elia, Belgium's Electricity Transmission System operator [Online]. Available: http://www.elia.be/en/grid-data/power-generation/wind-power

[27] EIGRID, Ireland's Electricity Transmission System Operator [Online]. Available: http://www.eirgrid.com/operations/systemperformancedata/windgeneration/

[28] J. M. Morales, S. Pineda, A. J. Conejo, and M. Carrion, "Scenario reduction for futures market trading in electricity markets," IEEE Trans. Power Syst., vol. 24, no. 2, pp. 878-888, May 2009.

[29] A. Ahmadi-Khatir, A. J. Conejo, and R. Cherkaoui, "Multi-area unit scheduling and reserve allocation under wind power uncertainty," IEEE Trans. Power Syst., vol. 29, no. 4, pp. 1701-1710, Jul. 2014.

[30] A. Nasri, S. J. Kazempour, A. J. Conejo, and M. Ghandhari, "Network-constrained AC unit commitment under uncertainty: A Benders' decomposition approach," IEEE Trans. Power Syst., to be published.

[31] X. Cheng and T. J. Overbye, "PTDF-based power system equivalents," IEEE Trans. Power Syst., vol. 20, no. 4, pp. 1868-1876, Nov. 2005.

[32] General Algebraic Modeling System (GAMS) [Online]. Available: http://www.gams.com/

Ali Daraeepour (S'13) received the B.Sc. degree from Azad University, Iran, in 2005, and the M.Sc. degree from Semnan University, Semnan, Iran, in 2008. He is currently pursuing the Ph.D. degree at the Nicholas School of the Environment at Duke University, Durham, NC, USA.

He was a Senior Engineer at the Iran Grid Management Company (IGMC), Tehran, Iran, between 2009 and 2012. His research interests include planning, economics and regulation of electric energy systems, and environmental and electricity policy.

S. Jalal Kazempour (S'08-M'14) received the B.Sc. degree from the University of Tabriz, Tabriz, Iran, in 2006, the M.Sc. degree from Tarbiat Modares University, Tehran, Iran, in 2009, and the Ph.D. degree from the University of Castilla-La Mancha, Ciudad Real, Spain, in 2013, all in electrical engineering.

In 2014, he was a postdoctoral fellow at the Whiting School of Engineering, Johns Hopkins University, Baltimore, MD, USA. He is currently a postdoctoral fellow at the Department of Electrical Engineering, Technical University of Denmark, Kgs. Lyngby, Denmark. His research interests include power systems, electricity markets, optimization, and its applications to energy systems.

Dalia Patiño-Echeverri received the B.S. and M.Sc. degrees in industrial engineering from the University of the Andes, Bogotá, Colombia, and the PhD degree in engineering and public policy from Carnegie Mellon University, Pittsburgh, PA, USA.

She is currently an Assistant Professor at the Nicholas School of the Environment at Duke University, Durham, NC, USA, where she studies the economic and environmental impacts of power generation technologies, market rules, and policies affecting capital investment and operating decisions within the electricity industry.

Antonio J. Conejo (F'04) received the M.S. degree from the Massachusetts Institute of Technology, Cambridge, MA, USA, in 1987, and the Ph.D. degree from the Royal Institute of Technology, Stockholm, Sweden, in 1990.

He is currently a Full Professor at The Ohio State University, Columbus, $\mathrm{OH}$, USA. His research interests include control, operations, planning, economics and regulation of electric energy systems, as well as statistics and optimization theory and its applications. 